\title{
INCERTEZA QUÂNTICA E DILACERAMENTO DO ESPÍRITO: REFLEX ÕES HEGELIANAS SOBRE A CIÊNCIA CONTEMPORÂNEA
}

\author{
Sinésio Ferraz Bueno ${ }^{1}$ \\ Universidade Estadual Paulista (UNESP) \\ (iD) https://orcid.org/0000-0003-3124-4692 \\ E-mail: sinesioferraz@yahoo.com.br
}

\section{RESUMO:}

Desde a formulação do princípio de incerteza, a pesquisa em física quântica suscitou um dilema filosófico basicamente centrado na oposição entre "realistas", favoráveis aos pressupostos de uma objetividade forte, e "idealistas", inclinados aos fundamentos de uma objetividade fraca. A hipótese central deste artigo, é que esse dualismo, assim como o problema clássico do solipsismo da consciência, pode ser devidamente compreendido como etapa do desenvolvimento da autoconsciência do espírito, nos moldes conceituais da filosofia de Hegel.

PALAVRAS-CHAVE: Hegel; Metafísica; Idealismo; Solipsismo; Física quântica.

\section{QUANTUM UNCERTAINTY AND TEARING OF THE SPIRIT: HEGELIAN REFLECTIONS ON CONTEMPORARY SCIENCE}

\begin{abstract}
:
Since the formulation of the uncertainty principle, research in quantum physics has raised a philosophical dilemma basically centered on the opposition between "realists", favoring the assumptions of strong objectivity, and "idealists", leaning on the foundations of weak objectivity. The central hypothesis of this article is that this dualism, as well as the classic problem of the solipsism of consciousness, can be properly understood as a stage in the development of the self-consciousness of the spirit, in the conceptual molds of Hegel's philosophy.
\end{abstract}

KEYWORDS: Hegel; Metaphysics; Idealism; Solipsism; Quantum physics.

\footnotetext{
${ }^{1}$ Doutor(a) em História e Filosofia da Educação pela Universidade de São Paulo (USP), São Paulo - SP, Brasil. Professor(a) da Universidade Estadual Paulista Júlio de Mesquita Filho (UNESP), Marília - SP, Brasil.
}

BUENO, Sinésio Ferraz. Incerteza quântica e dilaceramento do espírito: reflexões hegelianas sobre a ciência contemporânea. Griot : Revista de Filosofia, Amargosa - BA, v.22 n.1, p.186-202, fevereiro, 2022. 


\section{A extensão como fundamento da ontologia material}

Durante o contexto histórico que se estendeu desde o heliocentrismo de Nicolau Copérnico, na primeira metade do século XVI, até a física de Issac Newton, nas últimas décadas do século XVII, a modernidade assistiu a uma autêntica revolução na concepção teórica, na imagem e na metodologia da ciência. Essa transformação pode ser adequadamente sintetizada pela metamorfose conceitual que afetou profundamente a concepção acerca do mundo natural. As matrizes antigas, originalmente metafísicas, pelas quais a natureza era entendida como universo substancial dotado de qualidades divinas e transcendentes, foram decisivamente substituídas pela compreensão mecanicista e instrumental que até os dias de hoje converte o mundo natural como objeto de dominação. A ciência moderna, fundamentada no método experimental teoricamente concebido por Galileu e Descartes, desenvolveu uma autonomia progressiva em relação a concepções animistas e vitalistas sobre o mundo natural, passando a compreender a natureza sobretudo como substância extensa passível de tradução geométrica e matemática, e inteiramente alheia a qualquer tipo de finalismo metafísico. $O$ desprendimento da ciência moderna em relação a pesquisas acerca da essência ou substância dos fenômenos conduziu à hegemonia de um conhecimento cuja objetividade se concentra na comprovação experimental dos fatos e em sua independência radical em relação a pressupostos da antiga metafísica. Desde o início do período moderno, a Revolução Científica consagrou uma ontologia materialista, essencialmente baseada na homogeneidade e uniformidade da matéria, entendida como realidade extensa integralmente redutível a modelos explicativos mecanicistas, e completamente desprovida de qualidades animistas ou espirituais.

A adoção do mecanicismo como parâmetro ontológico para a compreensão da realidade implicou na redução dos fenômenos físicos da natureza a movimentos corpóreos desconectados de horizontes finalistas metafísicos. É importante assinalar que em termos filosóficos o mecanicismo é inteiramente dependente da concepção substancialista da extensão, pois é esta que legitima a própria separação entre sujeito cognoscente e objeto do conhecimento. Nesse sentido, é possível afirmar que todo o edifício filosófico da ciência moderna seria decisivamente abalado caso se pudesse suspeitar acerca da inconsistência da extensão como fundamento ontológico do mundo material. A mais incisiva contestação da extensão como substância dos corpos materiais foi realizada por George Berkeley, em sua obra Três ensaios sobre Hilas e Filonous, dedicada a contestar a existência de qualidades primárias supostamente originadas de corpos e objetos materiais. Para o filósofo, a extensão jamais poderia ser uma qualidade primária e substancial, pois ela é somente uma ideia cuja consistência em si mesma é inseparável das sensações que em seu conjunto constituem a percepção empírica de qualquer entidade material. Como a extensão é inseparável de outras sensações como solidez, peso e movimento, pelas quais a ideia da existência de corpos e objetos materiais independentes da percepção pela mente humana se torna possível, isso significa que a extensão jamais poderia ser uma qualidade ontológica e substancial da matéria. Pelo contrário, a própria extensão já é dependente de uma concepção substancialista da matéria, pois ela somente adquire sentido em conexão com corpos e objetos materiais dos quais ela supostamente seria um sustentáculo. Berkeley demonstrou, de maneira logicamente primorosa, a impossibilidade de que a extensão seja uma propriedade substancial da matéria, pois ela própria já é tributária da existência independente da matéria: "E pode, Hilas, uma coisa estender-se sem extensão? Ou não está a ideia de extensão necessariamente inclusa na de estender-se?" (BERKELEY, 1980, p. 69).

\section{O dilema filosófico da física quântica}

No século XX, as pesquisas científicas no campo da física quântica, dedicadas ao estudo das entidades ultramicroscópicas dos corpos materiais, foram as responsáveis pela produção de 
hipóteses teóricas intimamente relacionadas com o imaterialismo de Berkeley. Os pesquisadores da física quântica produziram grande abalo no mundo científico, ao apresentarem constatações empíricas de que as menores entidades constituintes da matéria existem em estado de dualidade, podendo se comportar tanto como partículas corpusculares, mas também em formato ondulatório e completamente avesso à aparência sólida e extensa que é peculiar à física clássica. Para um entendimento resumido da ruptura estabelecida pela física quântica frente aos pressupostos mecanicistas da ciência, é relevante uma breve apresentação do princípio de complementaridade, formulado por Niels Bohr, e do princípio de incerteza, de Werner Heizenberg.

O princípio de complementaridade de Bohr designa o comportamento dualístico que caracteriza os fenômenos mecânicos em sua realidade subatômica, relativa a dimensões da escala de Planck, equivalentes a $10^{-33} \mathrm{~cm}$. Nessas condições, diversos experimentos demonstraram algo que se convencionou denominar como comportamento contraintuitivo dos objetos quânticos, pois a configuração corpuscular ou ondulatória está condicionada à observação direta realizada pelos pesquisadores. Quando tais entidades (elétrons, fótons, bósons, quarks, etc.) são observadas por um ser humano, elas assumem um formato corpuscular compatível com a aparência sólida e extensa à qual o senso comum cotidiano está habituado. Mas em condições experimentais em que a imagem da trajetória dos objetos subatômicos não é diretamente registrada em telas detectoras visualizáveis pelos pesquisadores, tais entidades assumem um padrão ondulatório incompatível com a extensão material. Os experimentos quânticos revelaram que a natureza das entidades constituintes da realidade é em si mesma incongruente com o mecanicismo cartesiano-newtoniano, uma vez que o universo quântico existe em um estado de complementaridade onda/partícula. É a observação humana dos objetos quânticos que produz o colapso do formato ondulatório, determinando o aspecto corpuscular que é próprio à existência cotidiana. Em termos filosóficos, que serão desenvolvidos ao longo deste artigo, é possível dizer que a ontologia materialista e mecanicista que caracteriza a ciência clássica é uma abstração produzida pela consciência.

Juntamente com a complementaridade de Bohr, o princípio de incerteza, formulado por Heisenberg, é o fundamento central da Escola de Copenhagem, e significa a mais expressiva ruptura científica com os princípios deterministas da física clássica. A incerteza formulada por Heisenberg consiste na impossibilidade de determinação de valores exatos para a localização espacial e para a velocidade dos objetos quânticos em um momento específico do tempo. Os valores atribuíveis à velocidade e à posição espacial coexistem em uma relação inversamente proporcional que é intrínseca todos os experimentos de laboratório. Quando se utilizam feixes de luz para iluminar a posição de um elétron, os fótons empregados provocam efeitos mecânicos que aumentam a velocidade do objeto em questão, impossibilitando sua localização espacial exata. Caso se tente corrigir essa interferência, pela diminuição da intensidade dos feixes de luz, a visualização do elétron é decisivamente comprometida. Na medida em que se constata de maneira irreversível a impossibilidade de determinação precisa e simultânea da velocidade e da localização do objeto quântico no espaço, fenômeno inteiramente em desacordo com a física clássica, Heisenberg constatou a incerteza como princípio intrínseco dos fenômenos quânticos. O princípio de incerteza de Heisenberg explicita a dissonância irredutível entre os conceitos newtonianos clássicos, que asseguram uma descrição determinista dos fenômenos físicos, e a realidade quântica, que se caracteriza pela impossibilidade de descrições exatas e realistas.

A integração das pesquisas realizadas por Bohr e Heisenberg conflui para uma descontinuidade muito significativa entre uma ontologia materialista, que era própria ao mecanicismo da física clássica, e uma nova forma de compreensão dos fenômenos físicos de natureza atômica, que é inteiramente contrária às concepções de realismo e de determinismo da ciência moderna. A diferença entre a física clássica e a física quântica, no que se refere a uma compreensão filosófica da realidade, pode ser sintetizada mediante duas posições distintas, que desde as formulações originais da Escola de Copenhagem, representaram trajetos antagônicos na interpretação sobre o que é o "real". Diante da importância central do observador humano para 
a própria constituição da realidade corpuscular e aparentemente sólida e extensa que caracteriza o senso comum cotidiano, assim como perante a impossibilidade de conhecimento exato e determinista dos fenômenos quânticos, configurou-se um dilema central de natureza filosófica. Esse dilema consiste em indagar se a incerteza reinante nos fenômenos quânticos é um problema de natureza epistemológica, resultante da incapacidade atual dos métodos e instrumentos de conhecimento disponíveis, ou se trata de um problema de natureza ontológica, que diz respeito à constituição da realidade em si mesma (ARROYO, 2015, p. 16).

$\mathrm{O}$ dilema filosófico entre a natureza epistemológica ou ontológica acerca da incerteza e indeterminismo dos fenômenos quânticos encontrou uma tradução própria ao campo das investigações científicas no dualismo entre posições "idealistas", centradas na primazia do papel do observador humano, e posições "realistas", baseadas na explicação do colapso quântico como resultado da interferência dos aparelhos de medição. $O$ grande argumento dos pesquisadores contrários ao idealismo consiste no caráter irredutível do aparato técnico de medição, que aponta para a impossibilidade de estabelecimento preciso das fronteiras entre o universo macroscópico e mecanicista, e o universo subatômico: "o ponto essencial é que o cientista vive em mundo "clássico", ao passo que seu objeto de estudo são partículas microscópicas que habitam um mundo "quântico"'(PESSOA JR., 2001, p. 160). A disputa entre "realistas" e "idealistas" pode ser mais precisamente traduzida mediante o contraste, que se tornou obrigatório após as pesquisas subatômicas, entre aqueles que permaneceram ligados aos pressupostos tradicionais de uma objetividade em sentido "forte", isto é, baseada em um realismo mecanicista para o qual a realidade é composta por coisas estáveis, mensuráveis e espacialmente determináveis com exatidão matemática, e uma objetividade "fraca", relativa a fenômenos dualísticos, incertos e não-locais.

Dessa forma, o problema filosófico engendrado pela física quântica pode ser descrito pelo antagonismo entre uma questão epistemológica, relacionada a posições favoráveis à objetividade forte, e uma questão ontológica, baseada no indeterminismo da objetividade fraca. Para os partidários de uma objetividade forte, as entidades quânticas apresentam uma realidade objetiva que é completamente independente dos eventos experimentais e de sua observação. Dessa forma, se existe o quociente de indeterminação e incerteza dos fenômenos quânticos, ele não se relaciona com a realidade em si mesma, pois se deve à imprecisão inerente à própria distância entre o sujeito humano e seus instrumentos de análise, que são clássicos e macroscópicos, e os objetos investigados, que são de natureza quântica e sub-atômica. Por outro lado, para os "idealistas", que defendem a objetividade fraca, o realismo determinista, mecanicista e coisista não passa de uma ilusão positivista, passível de dissolução mediante a constatação do papel decisivo do observador humano para o colapso quântico e sua consequente produção de uma realidade corpuscular que é própria ao senso comum.

\section{O realismo quântico}

No âmbito das pesquisas em física quântica, o debate entre posições "realistas" e "idealistas" nas últimas décadas foi demarcado pela importância atribuída aos instrumentos de medição para a produção da descontinuidade entre o formato ondulatório e o formato corpuscular das entidades investigadas. Os defensores do realismo determinista e objetivista próprio à ciência tradicional reagiram às reflexões de viés metafísico que se tornaram muito comuns desde os primeiros estudos da Escola de Copenhagem mediante duas linhas argumentativas distintas. A reação mais direta, de natureza positivista, consistiu na pura e simples negação da própria relevância científica do problema, dada sua inverificabilidade empírica (PESSOA JR., 1992). Entre os pesquisadores que trabalharam na formulação de explicações teóricas alternativas à posição idealista, o foco teórico esteve concentrado na compreensão dos possíveis fatores objetivos responsáveis pelo colapso quântico. A meta estabelecida consistiu, então, em definir com a maior precisão possível o 
momento em que o sistema ondulatório sofre uma fratura que determina a configuração corpuscular que é peculiar à realidade macroscópica, sem que se possa atribuir qualquer importância à observação humana nesse processo. No campo da física quântica, esse conjunto de problemas ficou conhecido como "problema da medição", pois as pesquisas se concentram na determinação do momento exato em que, por interferência dos instrumentos de medição, ocorreria o colapso quântico. Sob esse pressuposto teórico, a descontinuidade entre o formato ondulatório e o formato corpuscular configuraria exclusivamente uma questão de natureza epistemológica, diretamente relacionada ao papel decisivo das condições experimentais de medição na determinação das propriedades físicas do mundo material.

No campo das pesquisas em física quântica o "problema da medição" ensejou uma grande quantidade de modelos teóricos significativamente diferentes entre si, baseados na pesquisa comum de uma explicação não metafísica para a discrepância entre o mundo quântico e o mundo clássico. Elas se diferenciam de uma interpretação ontológica acerca do colapso ondulatório por concordarem mutuamente que o papel do sujeito observador deve ser substituído pelo aparato instrumental de medição. Não é objetivo da presente reflexão uma descrição dos diferentes modelos teóricos produzidos nas últimas décadas com o objetivo de fornecer uma explicação exclusivamente física para o colapso quântico. Com propósitos unicamente ilustrativos, que não devem nos afastar do foco filosófico deste artigo, farei breve menção a uma das principais abordagens do problema da medição, dado seu antagonismo direto em relação às interpretações "idealistas". Trata-se do "programa de amplificação termodinâmica", que se baseia na hipótese teórica de que a ruptura entre o mundo quântico e o mundo clássico estaria exclusivamente relacionada com o processo de amplificação do sinal emitido por entidades quânticas quando estas incidem em placas detectoras que aumentam sua energia em um milhão de vezes, para que as informações possam ser detectadas por um osciloscópio (PESSOA JR., 2001, p. 6). Em virtude da amplificação, que é incondicionalmente necessária para a interpretação das informações do mundo quântico pelo observador humano, a passagem do formato ondulatório para o formato corpuscular se daria de maneira irreversível no momento da interferência macrofísica e termodinâmica sobre os processos quânticos, sem que o observador humano tenha qualquer importância nesse processo exclusivamente físico.

A explicação termodinâmica, assim como todas as outras teorias que procuram explicar o colapso quântico baseadas em argumentos de natureza exclusivamente física, esbarra em um obstáculo irredutível, que delimita justamente a diferença entre a física e a metafísica. Esse obstáculo diz respeito à impossibilidade de que a consciência humana possa ser pura e simplesmente eliminada do interior da cadeia de eventos experimentais que circunscrevem a medição. O problema da explicação do colapso quântico se coloca de maneira radicalmente diferente entre pesquisadores inclinados a explicações metafísicas e aqueles que adotam modelos teóricos baseados na objetividade forte e determinista. Pois para o metafísico o postulado idealista de que o colapso da função de onda é provocado pela observação por um sujeito humano é logicamente consistente como causa de si mesmo e prescinde inteiramente de argumentos acessórios de natureza empírica. Quando se assume a interferência decisiva da consciência humana na passagem do mundo quântico ao mundo clássico, esse argumento especulativo é suficiente por si só, desde que consideremos a consciência como esfera de interioridade substancial e autônoma. Para pesquisadores alinhados ao determinismo da objetividade forte, o desafio é muito mais espinhoso, pois o método experimental consagrado pela Revolução Científica exige que os postulados teóricos estejam robustamente fundamentados em demonstrações empíricas que garantam sua consistência lógica. Em relação a esse problema, a descontinuidade entre o âmbito ultramicroscópico das entidades clássicas e o universo macroscópico e corpuscular, aparece como um obstáculo intransponível, pois é impossível delimitar de maneira exata e indiscutível o momento em que a medição determina o colapso da função de onda. Por mais que os pesquisadores se esforcem em isolar os objetos quânticos e o aparato técnico de medição do contato direto com 
o observador humano, o processo de medição em si mesmo somente poderá ser completado pela observação realizada por uma consciência humana. E nesse momento, por mais cautelosa que tenha sido a metodologia empregada para isolar o sistema de medição, a simples presença do sujeito humano devolve à metafísica uma primazia explicativa irredutível.

\section{Idealismo quântico e o problema do solipsismo da consciência}

O caráter ineliminável da consciência humana no processo de medição dos fenômenos quânticos originou um trajeto progressivo de valorização idealista nesse campo da ciência. Após os trabalhos pioneiros da Escola de Copenhagen, o mais expressivo programa de pesquisa relacionado a concepções ontológicas subjacentes à física quântica foi empreendido por John Von Neumann, cientista que se dedicou ao estudo da consistência interna das teorias da medição. O argumento central postulado por ele consiste em uma demonstração do caráter substancial da consciência humana na cadeia de medição, baseado no paradoxo clássico da regressão infinita que se impõe necessariamente sempre que se busca contornar a presença do observador humano. Quando o processo de medição é concebido somente pela interação entre fenômenos quânticos e instrumentos de medição, a simples constatação de que o aparato técnico macroscópico é quântico em si mesmo, torna a medição um processo que nunca se completa, dada a necessidade de que um segundo aparelho seja introduzido na cadeia de observação, ocasionando nova necessidade de observação por um terceiro instrumento. Em outras palavras, "se todos os objetos (microscópicos ou macroscópicos) são constituídos por objetos quânticos, então a interação entre um objeto quântico (a ser medido) e um aparelho de amplificação (a supostamente medir) não completaria uma medição" (ARROYO, 2015, p. 91-92). A única possibilidade de estabelecer a descontinuidade na cadeia de medição, para que o processo seja completado, reside na introdução da consciência humana no interior desse processo, dada sua condição ontológica de se situar para além dos limites que circunscrevem a causalidade mecânica própria aos objetos físicos: "é inteiramente correto que a medição ou o processo relacionado à percepção subjetiva é uma nova entidade em relação ao ambiente físico, e que não pode ser reduzido a este último. De fato, a percepção subjetiva nos conduz à vida intelectual interior do indivíduo, cuja natureza é extraobservacional" (VON NEUMANN, 1955).

A valorização da consciência como sujeito causal responsável pelo colapso da função de onda foi pesquisada por Fritz London e Edmond Bauer, para quem a ruptura decisiva estabelecida pela consciência se deve à faculdade de introspecção, que a situa em uma condição radicalmente independente da causalidade mecânica. Os autores endossam a interpretação subjetivista de Von Neumann, propondo "um estatuto ontológico privilegiado para a consciência individual do observador humano no universo" (ARROYO, 2015, p. 104). A qualidade substancial da consciência, de se constituir como esfera de interioridade privilegiada e autônoma em relação aos fenômenos físicos, permite que lhe seja atribuído um princípio causal fundante da própria materialidade do real: "há claramente o comprometimento ontológico com uma entidade mental que é causa de uma entidade material" (ARROYO, 2015, p. 104, itálico do autor). É importante observar que essa notável valorização da consciência como momento decisivo de descontinuidade na cadeia de medição supõe uma implicação filosófica altamente problemática no campo científico. Quando a uma consciência individual é atribuído o papel de colapsar a função de onda e produzir a objetividade do real, a consequência mais imediata desse pressuposto é que o solipsismo se torna o ponto de partida obrigatório para as reflexões no campo da física quântica. Se a interioridade subjetiva se torna um ponto inextenso causador da realidade objetiva, o solipsismo surge como horizonte aparentemente irredutível na cadeia de medição: "isto é, a implicação de que exista uma única subjetividade real e que todas as outras subjetividades sejam irreais ou ilusórias" (ARROYO, 2015, p. 104). 
A dimensão metateórica da consciência no interior do processo de produção da objetividade dos experimentos quânticos é um argumento mais adequado para a explicação filosófica do solipsismo, e foi aprofundada mediante experimentos mentais que exploraram o argumento da cadeia infinita sob o ponto de vista do observador humano. $O$ físico Eugene Wigner encarregouse de explorar a interpretação subjetivista de London e Bauer mediante um experimento mental que introduz o próprio observador humano no interior da cadeia de medição. Essa hipótese consiste em conceber como um sistema quântico composto a cadeia formada pelo objeto quântico microfísico, o aparelho de medição macrofísico e o observador humano. Essa configuração experimental apresenta o pressuposto de que os três elementos que a constituem, a saber, o objeto quântico, o aparelho e o observador humano, coexistem em uma condição hermeticamente isolada, em estado de superposição. Externamente a tais condições experimentais, um segundo observador humano é introduzido (o "amigo de Wigner"), com o papel de problematizar a interferência decisiva do observador no processo de construção da objetividade. $O$ experimento mental de Wigner pressupõe que o primeiro observador realiza uma medição que provoca o colapso da função de onda, produzindo um resultado objetivo. Mas o amigo de Wigner, ao observar o sistema quântico no qual o primeiro observador está inserido, também realiza uma medição, que provoca o colapso desse sistema mais amplo, que inclui o primeiro observador. É importante constatar que do ponto de vista do primeiro observador o sistema a ser colapsado consiste em um objeto e um aparelho de medição, ao passo que para o amigo de Wigner, o sistema a ser colapsado inclui também o primeiro observador. Na medida em que esse experimento mental implica na realização de duas observações por seres humanos distintos, cabe indagar a qual delas pode ser atribuída uma relevância ontológica, que consistiria no colapso que efetivamente produz a realidade macrofísica.

O experimento mental de Wigner é um artifício teórico análogo à cadeia de Neumann, pois sugere a perspectiva de uma sucessão infinita de observações em que a realidade é constituída de maneira radicalmente diversa, de acordo com a observação a ser realizada por cada um dos participantes da experiência. Dessa forma, se forem introduzidos em uma escala infinita observadores adicionais na experiência, cada um deles responsável por colapsar o sistema composto pelos participantes anteriores, o resultado será a existência de uma cadeia infinita de realidades, sem que seja possível estabelecer um critério objetivo para definir a prioridade ontológica a qualquer uma delas. Em outras palavras, na medida em que cada um dos observadores realiza o colapso quântico de um sistema em que há elementos em superposição, porém ele próprio está em estado de suspensão sob o ponto de vista do observador seguinte, o paradoxo exposto por Wigner remete ao solipsismo intrínseco a cada uma das observações. Todos os infinitos observadores de uma tal experiência física estariam mergulhados em uma concepção solipsista de realidade, para a qual somente sua própria observação seria efetivamente real, ao passo que as demais constituições da realidade, peculiares aos demais observadores, seriam ontologicamente irrelevantes. É importante observar que o experimento mental de Wigner não implica na existência de diferentes pontos de vista frente a uma realidade comum e idêntica a si mesma, mas na existência de infinitas realidades, constituídas pelo solipsismo de cada uma das consciências envolvidas. Diante dessa cadeia infinita de realidades, o isolamento solipsista de uma consciência específica em relação a todas as demais demarca a completa impossibilidade de que se possa estabelecer uma prioridade ontológica objetiva e externa capaz de definir uma concepção de realidade que seja válida e independente às infinitas consciências envolvidas. Quando as perspectivas teóricas de Von Neumann e de Wigner são integradas, ambas confluindo para o poder causal da consciência como produtora da realidade material, evidencia-se que a física quântica impõe duas constatações de natureza metafísica: "1) a consciência é imaterial, no sentido de que não pertence ao mesmo nível ontológico que os sistemas quânticos, isto é, deve ser considerada em um meta-nível em relação à aplicação da mecânica quântica; 2) a consciência não é subjetiva, isto é individualizada" (ARROYO, 2015, p. 115, em itálicos no original). 


\section{Deus}

Os mais importantes desenvolvimentos teóricos em física quântica posteriores à Escola de Copenhagem evidenciam um afunilamento idealista que elevou ao primeiro plano o problema do solipsismo da consciência. Erwin Schrödinger foi o cientista quântico que explorou de maneira filosoficamente lúcida os paradoxos aparentemente irresolvíveis que foram expostos pelos teóricos idealistas. Seu ponto de partida consistiu em expor e superar as antinomias subjacentes ao problema do solipsismo, mediante uma exposição kantiana do problema que é suscitado pela impossibilidade de conciliar a existência de um mundo estável e objetivo com o paradoxo aritmético do pluralismo das consciências responsáveis por sua produção: "será que o meu mundo é realmente igual ao seu? Existiria um único mundo real a ser distinguido de suas imagens introjetadas pelo modo de percepção dentro de cada um de nós? Em caso afirmativo, seriam essas imagens semelhantes ao mundo real ou seria este último o mundo 'em si', talvez bem diferente daquele que percebemos?" (SCHRÖDINGER, 1997, p. 102). A solução apresentada por Schrödinger para o paradoxo entre a unidade do mundo e a pluralidade das consciências consiste em reduzir metafisicamente o pluralismo das mentes à existência substancial de uma única consciência suprema que se manifesta no interior de cada singularidade consciencial humana: “para a filosofia, então, a verdadeira dificuldade reside na multiplicidade espacial e temporal de observar e pensar. Se todos os eventos ocorressem em uma consciência, toda a situação seria extremamente simples" (SCHRÖDINGER, 1964, p. 18). Schrödinger baseia sua reflexão no pensamento védico indiano dos Upanishads, textos filosóficos, produzidos por sábios indianos entre VIII e IX aC. Segundo essas fontes, o mundo material é efeito de uma estrutura transcendental que é imanente a todas as consciências individuais: "de maneira resumida, é a visão de que todos nós, seres vivos, estamos unidos pois somos, na verdade, aspectos de um único ser, que talvez, na terminologia ocidental, possa ser chamado de Deus, enquanto nos Upanishads seu nome é “Brahman"” (SCHRÖDINGER, 1964, p. 95).

Conforme abordamos anteriormente, o problema filosófico engendrado pela física quântica consiste na oposição entre uma objetividade "forte", para a qual existe uma realidade "em si" que é completamente independente da obervação realizada pelo sujeito humano, e uma objetividade "fraca", baseada na incerteza, dualidade e não-localidade intrínsecas aos fenômenos quânticos. $O$ afunilamento idealista das pesquisas científicas nas últimas décadas baseou-se em postulados progressivamente contestadores do realismo mecanicista que entende a realidade como um conjunto de coisas estáveis, mensuráveis e matematicamente determinadas. $\mathrm{O}$ grande obstáculo para os partidários do realismo clássico está relacionado com a impossibilidade de eliminação da consciência humana no interior da cadeia de eventos experimentais que compõem o processo de medição. Mas o postulado idealista que atribui à consciência o papel decisivo de colapsar a função de onda e produzir o mundo material como um produto necessário da atividade subjetiva impõe o solipsismo como problema filosófico necessário das reflexões sobre a física quântica. $O$ experimento mental de Wigner, ao explorar o isolamento solipsista de cada consciência singular em relação a todas as demais, expõe a impossibilidade da prioridade ontológica de uma única realidade objetiva universalmente válida. $O$ problema do solipsismo no âmbito teórico da física quântica suscita uma antinomia entre a realidade objetiva e o pluralismo quantitativo das consciências humanas, questão para cuja resolução o físico Schrödinger postulou a existência de uma estrutura transcendental imanente a todas as consciências humanas, que teria a qualidade ontológica de unificar a pluralidade das consciências em uma única entidade substancial e suprema. Essa explicação idealista para o problema teórico da relação entre sujeito e objeto no âmbito das pesquisas quânticas expõe o desenvolvimento da ciência ocidental a um paradoxo embaraçoso, uma vez que sugere implicitamente que o próprio progresso histórico da ciência 
conduziu necessariamente a uma inesperada prioridade da metafísica idealista como fundamento explicativo da realidade.

\section{O idealismo absoluto de Hegel}

O antagonismo produzido pela física quântica no campo filosófico pode ser resumido, conforme abordamos, na oposição entre uma explicação de natureza epistemológica, associada a uma objetividade forte, para a qual os fenômenos quânticos são completamente independentes dos eventos experimentais e sua observação, e uma explicação de natureza ontológica, associada à objetividade fraca, para a qual o realismo mecanicista e determinista é uma ilusão positivista dissolvida pelo colapso quântico produzido pela observação do sujeito. A plena compreensão dessa oposição entre "realistas" e "idealistas" no campo filosófico requer que o problema seja situado à luz da diferença suscitada pelos dois sistemas conceituais mais significativos da filosofia ocidental moderna: o idealismo transcendental de Kant e o idealismo absoluto de Hegel. Como se sabe, para Kant, a capacidade humana de conhecimento da realidade é rigidamente circunscrita pelos limites fenomênicos impostos ao entendimento (Verstand). O conhecimento é capaz somente de realizar uma síntese da experiência fenomênica que é condicionada pelas categorias inatas da sensibilidade e do intelecto, sendo incapaz de ir além da experiência. $O$ conhecimento da coisa-em-si, embora seja uma exigência inerente ao funcionamento da razão (Vernunft), constitui-se como ilusão estrutural, dada sua incognoscibilidade. O empreendimento filosófico de Hegel pressupõe justamente que o conhecimento racional do mundo realizado pela ciência permanece dogmático e ilusório caso não busque transgredir tais limites kantianos, pois eles nada mais são que entraves postos pelo próprio entendimento, e por isso devem ser compreendidos e superados. Com esse objetivo, a crítica de Hegel se dirige de maneira nuclear ao método mecanicista e positivista do entendimento, que almeja reduzir a realidade a constantes matemáticas. Nesse sentido, a análise hegeliana do entendimento pode ser devidamente compreendida como uma crítica aos pressupostos mecanicistas, deterministas e coisistas da objetividade forte, que na segunda metade do século XIX era encarnada pela física newtoniana. Dos limites kantianos até o idealismo hegeliano, a razão se vê diante de um movimento de autocompreensão que irá culminar na concepção do conhecimento como resultado do trabalho do espírito. Os dilemas quânticos constituem-se como desdobramentos históricos desse processo de desenvolvimento da consciência de si como núcleo ontológico da realidade.

Na medida em que dermos crédito ao afunilamento idealista que envolve a física quântica, torna-se possível pensar que o próprio desenvolvimento do método experimental da ciência ocidental conduziu a um primado idealista no qual a consciência se converte no núcleo irredutível que origina a realidade objetiva. Em grande medida, o sistema filosófico de Hegel antecipou em termos puramente especulativos uma compreensão dos dilemas da física quântica entre objetividade forte e objetividade fraca como momentos necessários do desenvolvimento histórico da consciência. Hegel concebeu como lei interna do processo de autoconsciência da razão que esta pudesse se compreender como experiência imanente na história: "a Dialética é a experiência que a consciência tem de si mesma" (HARTMANN, s/d, p. 375). O movimento de autoconsciência da razão, que é a mola propulsora da própria realização do Espírito Absoluto, implica na superação da mentalidade positivista para a qual o mundo objetivo é composto por uma realidade material inteiramente alheia ao sujeito humano. A superação da alienação da razão implica na autocompreensão acerca da segurança ilusória consagrada pelo positivismo, de que o conhecimento objetivo seja completamente independente dos sujeitos humanos que fazem a história. Pelo contrário, a autocompreensão da razão requer o reconhecimento de que o objeto não é uma coisa-em-si separada do sujeito cognoscente, uma vez que o próprio sujeito deve saber se reconhecer por trás do véu que encobre a aparência que ele mesmo produziu: "não há verdade que, em última análise, não se relacione essencialmente com o homem concreto, e que não seja verdade 
do sujeito. $\mathrm{O}$ mundo será hostil e falso enquanto o homem não destruir a objetividade e se reencontrar, bem como à sua própria vida, "por trás" das formas rígidas das coisas e das leis" (MARCUSE, 1978, p. 114).

A oposição entre um suposto mundo concreto e material e o sujeito cognoscente, consiste em dualismo a ser reconhecido e superado pela consciência, para que seu estranhamento em relação ao mundo possa dar lugar à unidade do espírito consigo mesmo. Ora, na medida em que a independência do mundo concreto nada mais é que resultado necessário do processo de secularização realizado pela ciência, a superação do dualismo entre a consciência e o mundo material dos objetos supostamente existentes em si mesmos é justamente o obstáculo que se apresenta à evolução do espírito. A fenomenologia do espírito de Hegel pressupõe uma teleologia cujo movimento exige a superação de diversas oposições entre homem e natureza, culminando no reconhecimento de que o espírito humano é veículo de realização do Espírito Absoluto, ou Deus. Uma vez que Deus se corporifica vitalisticamente tanto na natureza inanimada quanto nos seres vivos, adquirindo sua máxima consumação nos seres humanos dotados de consciência, os horizontes finalistas que justificam a existência da vida encontram sua mais plena realização em uma subjetividade livre que adquire plena consciência de si mesma:

O universo é a corporificação das funções vitais de Deus, isto é, das condições de sua existência. Mas ele também é inteiramente uma expressão de Deus, isto é, algo posto por Deus visando manifestar o que ele é. Por isso, o universo deve tanto ser apreendido como algo análogo a uma forma de vida, logo, deve ser entendido mediante a categoria da 'teleologia' interna', derivada do aristotelismo, quanto deve ser interpretado como algo análogo a um texto em que Deus diz o que ele é (TAYLOR, 2014, p. 114).

\section{Da consciência infeliz à consciência de si}

A autoconsciência do espírito requer antes de mais nada a contestação da certeza da existência de coisas independentes, existentes em si mesmas e desconectadas do movimento teleológico do Espírito Absoluto. Na obra Fenomenologia do Espírito de Hegel, a exposição acerca da incapacidade intelectual e cognitiva do entendimento é desdobrada em momentos de progressiva complexidade. Embora o objeto aparente ser essencial, e a consciência cognoscente pareça ter papel inessencial no processo do conhecimento, o filósofo demonstra que o exame atento da experiência revela exatamente o contrário, pois "essa certeza se faz passar a si mesma pela verdade mais abstrata e mais pobre" (HEGEL, 2002, p. 85). Um momento central da reflexão hegeliana, que procura demonstrar o caráter irredutível da mediação subjetiva na produção de um conhecimento objetivo sobre o mundo consiste na problematização daquilo que constitui internamente todo objeto de conhecimento: seu duplo caráter de unidade e multiplicidade de qualidades. Embora todo objeto de conhecimento aparente ser uma unidade idêntica a si mesma, esse caráter uno se revela, a um exame mais atento, como sustentáculo de múltiplas qualidades que são universais em si mesmas, e estão presentes em outro objetos singulares. $O$ próprio Hegel exemplifica essa contradição entre o uno e o múltiplo recorrendo a um grão de sal, que é um objeto singular, porém ao mesmo tempo contém qualidades que são universais: é branco, cúbico, dotado de determinado sabor, etc. $\mathrm{O}$ objetivo visado por Hegel consiste em demonstrar que todo objeto de conhecimento não pode ser reduzido a mera coisa completa e subsistente em si mesma, dada sua unidade, e ao mesmo tempo, sua multiplicidade de qualidades: unidade da unidade e da nãounidade. Quando a consciência procura contornar essa dialética ontológica que constitui internamente toda a realidade, ela se vê diante de paradoxos incompatíveis com a lógica elementar: 1) se o objeto for uma unidade simples e idêntica a si mesma, como seria possível diferenciá-lo de outros objetos? 2) se, pelo contrário, o objeto for múltiplo em si mesmo, e destituído de unidade interna, como será possível que suas múltiplas qualidades subsistam sem contar com um sustentáculo interno? Jean Hyppolite desenvolve esse paradoxo partindo do 
próprio exemplo dado por Hegel acerca do grão de sal: "se tais matérias se interpenetram, sua independência desaparece e só resta uma coisa única sem determinações; se estão justapostas, sua independência está salva, mas é a coisa única que está perdida e, com isso, voltamos à essência objetiva, poeira das partes que são partes de nada e têm, elas próprias, partes ao infinito" (HYPPOLITE, 1999, p. 127).

Ao longo de um trajeto gradativo de contestação da separação entre sujeito cognoscente e objeto do conhecimento, a meta visada pela reflexão somente se realiza quando a consciência atinge as condições para o pleno reconhecimento de si mesma como mediação fundamental da realidade fenomênica. $O$ resultado final dessa problematização em que os momentos de unidade e multiplicidade são alternadamente atribuídos à coisa e ao sujeito cognoscente, demonstra a insuficiência estrutural de um conhecimento em que os dois polos não são considerados em sua condição dialética de mediação recíproca. Para Marcuse, "todas essas tentativas para escapar à contradição, servem apenas para demonstrar que ela é inevitável, e constitui o verdadeiro conteúdo da percepção. A coisa é em si mesma unidade e diferença, unidade na diferença" (MARCUSE, 1978, p. 109). Para Hyppolite, "é a coisa que se reflete em si e para si mesma como o que é diferente do que ela é para outro (para nossa consciência, precisamente). Ora é una quando se mostra múltipla, ora é múltipla quando se mostra una: inclui em si uma verdade oposta a si, ela é uma contradição" (HYPPOLITE, 1999, p. 130). A análise da percepção revela um idealismo irredutível que é imanente à própria constituição da realidade objetiva, radicalizando o empreendimento de dissolução da coisa como objeto completo, independente e idêntico a si mesmo. O desenvolvimento da constituição dialética da própria realidade expõe o caráter sofístico e artificioso do senso comum e do positivismo posterior a Hegel para preservar a separação entre sujeito e objeto, bem como para salvar a concepção da independência das coisas em relação à consciência cognoscente. Essa é, para Hegel, a vida do Absoluto: "a unidade da unidade e da multiplicidade, a identidade da identidade e da não-identidade" (HYPPOLITE, 1999, p. 131).

Em seu processo de autoconhecimento, a consciência cognoscente descobre que o objeto de conhecimento deixa de ser uma entidade extensa, estável e idêntica a si mesmo, para converter-se em um universal incondicionado que é a síntese dialética entre unidade (ser-para-si) e multiplicidade (ser-para-outro). Essa contradição afeta igualmente os esforços realizados pela consciência para enunciar leis universais que visam ao enquadramento da instabilidade fenomênica sob grandezas matemáticas. Embora a física newtoniana tenha consagrado a redução do movimento realizado pelas forças naturais a constantes matemáticas universais passíveis de enunciação sob a forma de leis fixas e racionalmente inteligíveis, é forçoso reconhecer o caráter intelectualmente artificioso do empreendimento da ciência. A conexão habitual e constante constatada pelo intelecto entre eventos diversos que ocorrem na natureza espelha uma instabilidade fenomênica que somente se torna inteligível graças à sua redução a um "mundo calmo das leis" que permanece estranha ao movimento efetivo dos objetos. O realismo determinista da objetividade forte oculta um movimento tautológico e formal que o entendimento realiza consigo mesmo, pois o mundo calmo das leis "enuncia somente o modo de se relacionar de grandezas envolvidas em modelos de processos, fazendo abstração das próprias relações efetivas entre os verdadeiros elementos implicados na ação" (MARTINHO, 2010, p. 114). Para Hegel, embora a física newtoniana tenha se constituído como expressão exata da racionalidade da natureza, a dissolução dos objetos de conhecimento como entidades estáveis e autônomas evidencia que as leis físicas expõem o caráter tautológico e formal do entendimento em sua relação consigo mesmo. Em outras palavras, na medida em que o objeto não se constitui como entidade mecânica e dotada de realismo coisista, para Hegel, a própria física newtoniana padecia da incapacidade de descrever a suposta ontologia materialista e mecanicista propagada pela ciência, restringindo-se forçosamente aos parâmetros de uma objetividade fraca.

Ao final do percurso reflexivo hegeliano, chega-se à conclusão de que a incapacidade intelectual e cognitiva do entendimento para conhecer a realidade em si mesma não se deve à 
existência de um abismo kantiano intransponível entre o sujeito e o objeto, mas sim ao pressuposto equivocado amplamente adotado pelo entendimento, de que o real se constitua de coisas autônomas, extensas e subsistentes em si mesmas. A formulação da existência de uma coisaem-si incognoscível se revela aparência filosoficamente inconsistente quando se considera que tanto a instabilidade fenomênica, quanto sua subsunção a parâmetros intelectivos sob a forma de leis matemáticas universais e necessárias, são postas pelo próprio entendimento. O véu que encobre a relação entre a aparência e a essência das coisas é resultado do desconhecimento pela consciência de que ela é o autêntico sujeito produtor da realidade objetiva. A fenomenologia do espírito é o trajeto que conduz, desde uma objetividade alienada, até a autoconsciência: "fica patente que por trás da assim chamada cortina, que deve cobrir o interior, nada há para ver; a não ser que nós entremos lá dentro - tanto para ver como para que haja algo ali que possa ser visto" (HEGEL, 2002, p. 132). Se, para Hegel, o espírito deve ser concebido como sujeito racional desenvolvendo suas crescentes potencialidades, sua autoconsciência é realizada no interior de um processo de superação dialética de formas rígidas e limitadas que são o produto necessário de seu próprio desenvolvimento na história. A principal implicação da autoconsciência do espírito consiste em que não existe conhecimento verdadeiro que não esteja incondicionalmente relacionado ao desenvolvimento da consciência. Marcuse resume com clareza a implicação crítica fundamental do sistema filosófico de Hegel em seu potencial de crítica à ciência positivista: "o mundo será hostil e falso enquanto o homem não destruir a objetividade morta e se reencontrar, bem como à sua vida, "por trás' das formas rígidas das coisas e das leis" (MARCUSE, 1978, p. 114).

\section{Dilema quântico e dilaceramento do espírito}

Na perspectiva da fenomenologia do espírito, é possível entender que a oposição entre "realistas", partidários de uma objetividade forte, e "idealistas", alinhados com a defesa de uma "objetividade fraca", reflete o dilaceramento espiritual que é próprio ao desenvolvimento histórico das pesquisas no campo da física quântica, espelhando o desconhecimento do processo de automovimento da consciência implicado nessa área da ciência. Sob a ótica de Hegel, é possível compreender a elevada relevância e, sobretudo, o acerto de Von Neumann, ao caracterizar a introdução da consciência humana como fator ontologicamente decisivo para o colapso quântico. A consciência, sendo esfera de interioridade autônoma em relação aos fenômenos físicos, assume, na perspectiva de Von Neumann, estatuto ontológico equivalente àquele atribuído ao sujeito espiritual na reflexão filosófica de Hegel. Nesse sentido, o dualismo entre realistas e idealistas no interior da física quântica é perfeitamente compatível com os percalços inerentes ao processo de autoconsciência do espírito, desde o seu ponto de partida, em que a certeza sensível parece garantir a existência de um mundo objetivo formado por objetos inteiramente independentes da consciência, até a descoberta de que é o próprio entendimento que se oculta por trás do véu encobridor da coisa-em-si. Nesse percurso, que explicita a realização histórica de um processo de dilaceramento do espírito, formulado por Hegel em termos essencialmente especulativos, a consciência é forçada a se desprender de suas ilusões "realistas", relacionadas com o determinismo mecanicista e coisista, e aceitar o fato de que o quociente de indeterminação e incerteza reinante nos fenômenos quânticos não se deve a nenhuma imprecisão nos instrumentos técnicos de análise, uma vez que ele reflete a centralidade da consciência como fundamento ontológico da realidade em si mesma.

O impulso que anima a consciência na produção de objetos aparentemente autônomos e subsistentes reflete o anseio de superação da exterioridade e estranheza da realidade perante o sujeito. Charles Taylor explicita a existência do desejo como impulso que visa sobretudo a eliminar a estranheza aparente da realidade, e por esse motivo o movimento da consciência somente poderá se contentar quando nenhum objeto real se mostrar como algo alheio à consciência: "é esse anseio

BUENO, Sinésio Ferraz. Incerteza quântica e dilaceramento do espírito: reflexões hegelianas sobre a ciência contemporânea. Griot : 
por integridade total que, para Hegel, está na base da aspiração da consciência de si, num primeiro momento, após versões brutas e irrealizáveis do objetivo, e em seguida, quando o ser humano tiver sido educado e elevado pelo conflito e pela contradição, até a coisa real" (TAYLOR, 2014, p. 176). Assim, se o desejo almeja uma integridade que visa à superação da estranheza diante do mundo, essa meta somente poderá ser atingida quando toda a realidade se mostrar como emanação do Espírito Absoluto. Essa meta se realiza na abertura da consciência ao conhecimento do mundo, o que implica em descartar qualquer tipo de solipsismo, ou de recolhimento interior puramente espiritual e separado da realidade física: "não há estratégia de recolhimento que possa nos proporcionar integridade" (TAYLOR, 2014, p. 177). Mas se a consciência é movida pelo desejo, que a leva a uma relação de negação da estranheza do mundo, a integridade visada pelo impulso desejante não pode ser alcançada somente pelo consumo dos objetos sensíveis, uma vez que estes, após serem incorporados, somente abrem caminho para o surgimento interminável de desejos sucessivos que jamais poderão ser plenamente saciados: "descubro, portanto, no curso dessa experiência, que o desejo não se esgota jamais e que sua intenção refletida me conduz a uma alteridade essencial" (HYPPOLITE, 1999, p. 177). A integridade visada pelo desejo supõe um sentido infinitamente mais extenso que não pode ser realizado pela simples negação dos objetos materiais: "o desejo é, em sua essência, outra coisa que não aquilo que, imediatamente, parece ser" (HYPPOLITE, 1999, p. 175). O alvo definitivo do desejo consiste em encontrar uma realidade que não seja mais estranha e se mostre capaz de subsistir ontologicamente para que a integridade visada pela consciência se mostre possível. Esse objetivo definitivo do desejo somente se realiza quando a consciência encontra a si mesma, mas para que isso se efetive, ela necessita da mediação de um outro desejo, vale dizer, de uma outra consciência de si: "o desejo se refere aos objetos do mundo; depois, a um objeto mais próximo de si mesmo, a Vida; enfim, a uma outra consciência de si, é o próprio desejo que se procura no outro, o desejo do reconhecimento do homem pelo homem" (HYPPOLITE, 1999, p. 175).

É graças ao desejo que a consciência não pode ser reduzida a uma condição solipsista de mera identidade consigo mesma, pois o impulso desejante a conduz não apenas a consumir os objetos concretos do mundo, mas também a buscar sua integridade mediante um objeto que possa se sustentar em si mesmo: "de modo que o desejo básico da consciência de si só pode ser satisfeito por outra consciência de si" (TAYLOR, 2014, p. 180). Na medida em que cada consciência de si, em sua singularidade, existe para si mesma, mas, ao mesmo tempo, existe em condição de exterioridade e estranheza para outra consciência de si, o desejo básico de reconhecimento somente poderá se realizar por meio da superação dessa desigualdade. Dessa forma, o reconhecimento mútuo das consciências de si exige que cada uma delas possa se espelhar na outra, pela mediação do desejo recíproco de reconhecimento: "somente sou consciência de si quando me faço reconhecer por outra consciência de si, e se reconheço a outra do mesmo modo" (HYPPOLITE, 1999, p. 180). O encontro paradigmático entre dois homens que se enfrentam em uma batalha que poderá envolver a própria vida de um deles significa muito mais do que uma simples luta bruta pelo poder, na medida em que explicita a estrutura dialética fundamental da formação da consciência de si. A integridade visada pelo desejo somente se realiza em sua modalidade mais plena de sentido quando dois homens se enfrentam movidos pelo objetivo essencial de serem reconhecidos como pessoa e não como simples coisa ou objeto desprovido de significado. É por esse motivo que em estágios ainda rudimentares da história, esse encontro, que é paradigmático para o próprio desenvolvimento histórico da sociedade política, culmina na obtenção do reconhecimento mediante o emprego da força bruta, e sem nenhuma condição de reciprocidade. A resolução inicial desse conflito, em que uma das partes é reconhecida como senhor, restando à outra a condição de escravo, consiste apenas na etapa primeira de um processo dialético que irá se desdobrar no curso da história, por meio da "supressão efetiva das relações de dominação e a instauração da sociedade política na sua essência universal como reino da liberdade realizada" (LIMA VAZ, 1981, p. 9). 
A dialética entre senhor e escravo descreve de maneira muito clara a impossibilidade de que o desenvolvimento da consciência de si possa ser estagnada em um estágio solipsista de isolamento do eu em relação ao mundo. Todo ser humano se constitui como uma consciência cuja existência é absoluta para si mesma, ao mesmo tempo em que existe como uma mera coisa vivente estranha para as outras consciências. Por esse motivo, "a consciência existe como uma potência negativa", na medida em que seu ser não se contenta com a simples existência coisificada e sem significado para as outras consciências (HYPPOLITE, 1999, p. 181). A integridade visada pelo desejo, que em sua relação com os objetos do mundo natural se contenta com o impulso negativo que dissolve a estabilidade de coisas aparentemente subsistentes em si mesmas, se vê diante de uma meta muito maior quando o objeto em questão é uma outra consciência humana. Diante do outro, a consciência contempla outro desejo, sendo confrontada pela completa inconsistência de uma identidade solipsista, condição ontológica que a obriga a ser reconhecida, para que possa reconhecer-se a si mesma, dessa forma, "é somente nessa relação das consciências de si que se atualiza a vocação do homem" (HYPPOLITE, 1999, p. 181). O combate de todos contra todos, que Tommas Hobbes entendeu como condição inerente ao estado de natureza, oculta, na perspectiva de Hegel, a própria vocação espiritual do homem, que exige o reconhecimento de si mesmo como consciência autônoma, objetivo que somente pode ser obtido pela mediação do reconhecimento alheio:

Toda a vida espiritual repousa sobre essas experiências que estão hoje superadas na história humana, mas que permanecem como sua base profunda. Os homens não têm, como os animais, somente o desejo de perseverar no seu ser, o ser-aí ao modo das coisas; têm o imperioso desejo de se fazerem reconhecer como consciência de si, como elevados acima da vida puramente animal, e essa paixão, para se fazer reconhecer, exige, por seu turno, o reconhecimento da outra consciência de si (HYPPOLITE, 1999, p. 184).

\section{Considerações finais}

A teleologia da consciência de si permite compreender da maneira mais clara possível a caracterização hegeliana do Absoluto como sujeito. Deus não é concebido como simples transcendência inacessível, em amor consigo mesmo, mas como estrutura finalística e necessária de um mundo cuja existência é indissociável de sua corporificação em entidades humanas finitas, que são seus representantes privilegiados. Nesse sentido, a dialética entre senhor e escravo, sendo o protótipo nuclear da história humana, espelha não somente os diversos estágios históricos e sociais da realização da consciência dos homens, mas também a necessidade absoluta da consumação da consciência de si de Deus. O objetivo essencial da consciência de si é a realização das potencialidades da subjetividade livre, racional e autoconsciente. O Espírito Absoluto é a totalidade cósmica que põe a si mesma, mediante um movimento racional que é imanente ao desenvolvimento da consciência de si. Charles Taylor apresenta uma definição eloquente para expressar o teor da identidade do sujeito humano como síntese entre identidade e não-identidade: “o ser humano é o veículo da vida espiritual do Geist”(TAYLOR, 2014, p. 130). A integridade total que é visada desde o início pela consciência, em seu conhecimento do mundo, e em sua busca de reconhecimento mediante outra consciência, somente pode ser perfeitamente consumada na superação da oposição interna do sujeito como espírito corporificado e ao mesmo tempo como veículo de realização do Espírito Absoluto. O Absoluto é sujeito cósmico que realiza um movimento de autoprodução de suas próprias condições de existência, exteriorizando-se no mundo e retornando a si mesmo, reconhecendo-se como razão autoconsciente, pela mediação das consciências humanas. Para Jean Hyppolite, "o espírito finito não é um aquém, ele supera a si mesmo, atraído constantemente rumo à sua transcendência, e tal superação é a cura possível de sua finitude" (HYPPOLITE, 1999, p. 553). A autocompreensão da consciência de si como unidade 
da unidade e da não-unidade, vale dizer, seu entendimento de si mesma como substância que somente se realiza pela mediação do outro, inaugura o próprio conceito de espírito:

Para nós, portanto, já está presente o conceito do espírito. Para a consciência, o que vema-ser mais adiante, é a experiência do que é o espírito: essa substância absoluta que na perfeita liberdade e independência de sua oposição - a saber, das diversas consciência-desi para si essentes - é a unidade das mesmas: Eu, que é Nós, Nós que é Eu. A consciência tem primeiro na consciência de si, como no conceito de espírito, seu ponto de inflexão, a partir do qual se afasta da aparência colorida do aquém sensível, e da noite vazia do além suprasensível, para entrar no dia espiritual da presença (HEGEL, 2002, p. 142).

O conceito hegeliano de espírito, entendido como síntese entre o finito e o infinito, vale dizer, como superação do dualismo entre a consciência humana e o Espírito Absoluto, antecipou a resolução do dilema suscitado pela física quântica sobre o solipsismo da consciência. Se para Hegel a consciência humana é veículo do Espírito Absoluto, essa concepção idealista do Absoluto como sujeito que se realiza pela mediação dos sujeitos humanos torna-se perfeitamente compatível com a interpretação de Schrödinger sobre a existência de uma estrutura transcendental imanente a todas as consciências humanas. A referência vedantina pela qual Schrödinger postulou um monismo idealista para explicar a existência de uma unidade suprema de todas as consciências não se constitui de forma alguma como uma perspectiva mística destinada a revestir os problemas da física quântica com mistérios de natureza religiosa. Seu argumento sobre a consciência suprema apresenta uma dimensão ontológica diretamente consistente com sua pesquisa científica: "a metafísica não é parte do edifício do conhecimento, mas é seu suporte, e sem ele nenhuma construção futura torna-se possível. Talvez se possa dizer que a metafísica se transforma em física no curso de seu desenvolvimento" (SCHRÖDINGER, 1964, p. 5). A continuidade entre física e metafísica estabelecida por ele se torna a mais expressiva validação da relevância do idealismo filosófico para o campo científico. Quando o argumento de Schrödinger é deslocado de sua referência mística vedantina e pensado à luz do idealismo hegeliano, ele se torna decisivo para a compreensão do dilema quântico entre "realistas" e "idealistas". A indagação sobre a natureza epistemológica ou ontológica da indeterminação experimentalmente constatada nos fenômenos quânticos pode, então, ser decidida como uma questão essencialmente ontológica, relativa à própria estrutura da realidade. A abordagem filosófica de Hegel é suficientemente eloquente para indicar que o realismo mecanicista e seu pressuposto de uma realidade estável e composta por objetos autônomos e subsistentes sempre se constituiu como "objetividade fraca".

Segundo Jean Hyppolite, "a consciência infeliz é o tema fundamental da Fenomenologia", uma vez que a exposição dos vários momentos de seu trajeto dialético na história explicita um processo de dilaceramento do espírito (HYPPOLITE, 1999, p. 205). O confronto entre "realistas" e "idealistas", suscitado no âmbito das pesquisas em física quântica constitui um momento essencial do desenvolvimento da consciência infeliz, pois expõe a oposição entre o apego ao coisismo próprio à objetividade forte e um olhar idealista que remete a consciência para além de si mesma. Os dilemas filosóficos que caracterizam a pesquisa em física quântica implicam na necessidade de ruptura radical com parâmetros clássicos da ciência ocidental. Mas se para os cientistas essa descontinuidade é fonte de angústia, para a reflexão hegeliana, ela espelha um momento necessário do desenvolvimento do espírito em seu trajeto de autoconhecimento: "a consciência de si é a subjetividade erigida em verdade, mas tal subjetividade deve descobrir sua própria insuficiência, experimentar a dor do Si que não chega à unidade consigo mesma" (HYPPOLITE, 1999, p. 205). Embora o caráter negativo que é intrínseco aos princípios de incerteza e complementaridade que caracterizam os estudos de Copenhagen tenha se constituído como fonte de inúmeras divergências entre os pesquisadores quânticos, tais consequências negativas são o resultado inevitável da desigualdade entre a consciência e seu conceito. $O$ engajamento da consciência na experiência de sua própria negatividade é protagonizado pelos 
pesquisadores quânticos, sem que eles tenham clara consciência disso, e é importante assinalar que nesse trajeto de infelicidade da consciência, ontologia e ética estão indissoluvelmente entrelaçadas. Se desde o início do período moderno o processo de secularização do mundo empreendido desde o aparato técnico e científico consagrou a hegemonia de uma racionalidade instrumental e desconectada de horizontes teleológicos, o dilaceramento do espírito atualmente implicado na física quântica anuncia potenciais historicamente inéditos para a superação dialética da razão instrumental. 


\section{Referências}

ARROYO, R.W. O problema ontológico da consciência na mecânica quântica. (Dissertação de mestrado). Maringá, Universidade estadual de Maringá, Programa de pós-graduação em filosofia, 2015.

BER KELEY, G. Três diálogos entre Hilas e Filonous. São Paulo, Abril cultural, 1980.

HARTMANN, N. A filosofia do idealismo alemão. Lisboa, Fundação Calouste Gulbekian, s/d.

HEGEL, G.W.F. Fenomenologia do Espírito. Petrópolis, Vozes, Bragança Paulista, USF, 2002.

HYPPOLITE, J. Gênese e estrutura da fenomenologia do espírito de Hegel. São Paulo, Discurso Editorial, 1999.

LIMA VAZ, H.C. de. Senhor e escravo - uma parábola da filosofia ocidental. São Paulo, Síntese, 1981, v. 8, n. 21.

MARCUSE, H. Razão e revolução - Hegel e o advento da teoria social. Rio de Janeiro, Paz e Terra, 1978.

MARTINHO, A.B. A gravitação universal como lei geral do entendimento na crítica hegeliana à fundamentação da ciência moderna. In: UTZ, K.; SOARES, M.C. (orgs.). A noiva do espírito: natureza em Hegel. Porto Alegre, EDIPUCRS, 2010.

PESSOA JR., O. O sujeito na física quântica. In: Oliveira, E.C. Epistemologia, lógica e filosofia da linguagem. Feira de Santana, UEFS, 2001.

SCHRÖDINGER, E. O que é vida? São Paulo, Editora da Unesp, 1997.

SCHRÖDINGER, E. My view of the world. Cambridge, University Press, 1964.

TAYLOR, C. Hegel - sistema, método e estrutura. São Paulo, Isto é, 2014.

VON NEUMANN, J. Mathematical foundations of quantum mechanics. Princeton, University Press, 1955.

Autor(a) para correspondência / Corresponding author: Sinésio Ferraz Bueno. sinesioferraz@yahoo.com.br 